\title{
Rock Art and Tourism in Tanzania: In Search for Innovations
}

\author{
Kiagho Bukheti Kilonzo \\ University of Dar es Salaam, Tanzania \\ kiaghokilonzo@gmail.com
}

\begin{abstract}
Although the tourism industry is currently the biggest source of foreign income in Tanzania, it has for many years been concentrating on Ngorongoro Conservation Area, Game Reserves and national parks, while neglecting rock art sites, which in fact, are among the potential tourism attractions. The author acknowledges the contribution of the former in tourism promotion, but innovation is of vital important for rapid development of tourism promotion. This paper explores factors that have made the rock arts of central Tanzania to remain a neglected topic to the general public. It does so together with demonstrating ideas to make Tanzanian rock art sites among the tourist attractions since they have been taken lightly and not realized in tourism promotion for over four decades regardless the fact that the country occupies the largest concentration of rock art in Eastern Africa. Nevertheless, Tanzania occupies the oldest history of human ancestors, which are Zinjanthropus, Homo habilis and Homo erectus. The factors that are keenly looked at, in this study, include protecting the sites from natural disasters, involving people living around the sites in protection measures, building hotels and camps around the sites and educating the general public about the sites. The author of this study believes that there is a need for innovations, not only for tourism promotions but also for proper exploitation of economic resources of the rock art sites to alleviate poverty at least from the family level, especially for people who dwell around these sites.
\end{abstract}

Keywords: rock art, rock paintings, Central Tanzania, promotion, attractions https://doi.org/10.26493/2335-4194-10.69-81

\section{Introduction}

This article argues that the Rock Art of Tanzania has not been given the tourist attention it deserves. Although Tanzania is blessed in having the largest concentration of Rock Art in Eastern Africa and the oldest history in the world, its potential seems not to have been felt strongly by Tanzanian and African communities, and, thus, it has not yet been realized in tourism promotion.

It is against this background that a library research and minor observations and interviews were launched to provide relevant information to write this paper.
There was no attempt made to conduct field research for this study. The study is an attempt at contributing some ideas that may make Tanzanian Rock Art sites popular tourist attractions. The rationale of this attempt comes from the fact that the potential of central Tanzanian rock paintings has been taken lightly. Such a step, among various benefits, would have a good contribution towards poverty alleviation for people living around areas of rock sites.

The Tanzanian rock paintings are believed to be over 40,00o years old, and the country is also associated with human ancestors, namely Zinjanthropus, 
Homo habilis, and Homo erectus, but no or very little efforts have been invested to exploit such ancestors to attract visitors to Tanzania.

Tourism in Tanzania stands as the biggest source of foreign revenue, but the traditional attraction sites have remained to be the national parks, conservation and game controlled areas, despite the fact that Rock Art has all the symptoms of cultural tourism.

It is further noted that, although African rock paintings became known to the outside world much earlier than those from other parts of the world, it seems that the western ones, for instance, have received wide publicity, a factor that has attracted some western scholars who have worked in Africa such as Willet (2005, p. 42) to charge, 'Paintings of animals have been reported in Mozambique as early as 1721, and the first mention was made of Bushmen paintings in South Africa in 1752, whereas the European ones were totally unknown until Marcelino Sanz de Sautuola's daughter, Maria accidentally looked up at the roof of the cave of Altamira in 1878.' Indeed, the cave art of Chauvet (a site which was discovered only in 1994) and Lascaux in France, including that of Altamira in Spain, have become some of the greatest tourist attraction sites in Europe. The Tanzanian rock paintings are over 40,00o years old according to Anati (1986) but very little is known about them. Tanzanian primary and secondary schools' curricula seem to neglect arts subjects as they do not include topics about Rock Art. These subjects ought to have made young Tanzanians aware of such cultural heritage in their country, rather than leaving it to art historians and museum staff.

Since tourism is a major driver of global economics, this paper is, therefore, intended to present alternative measures that the author suggests can revitalize the business of tourism promotion. The study done by Bailey and Richardson (2010), about a new economic framework for tourism decision-making shows that tourism is, and will continue to be, a major driver of economic vitality throughout the world. The paper then presents such alternative measures by elaborating Rock Art and the concept of tourism, and then discusses possible innovative measures that could enhance its management. Some tourism management personnel, art scholars and students are likely to benefit from the discussion.

\section{Rock Art in Tanzania}

Preliminary information that one with little knowledge of Rock Arts would definitely need from this paper in the first place is the meaning of Rock Art and the reason why it was done. Rock Art is the art which was done on surfaces of huge stones by using the petro glyphs or pictograph style (Masao, 2003). Petro glyphs, which is also known as engraving are carvings made on the rock surface by using a sharp object. Pictographs are paintings made by using a soft object like a brush or fingers. The rock artists used blood, fat that came from game animals and plant oil, cow dung, hyrax droppings mixed with urine, fat or water.

There are various reasons why Rock Art was painted. In his class presentation, Dr. F. Masao (2015) listed down some of the reasons. First, the rock artists responded to the phrase 'art for art's sake,' meaning it was done as a hobby to create art. Second, the Rock Art is associated with ancestors' worship. Animals were slaughtered at worshiping sites as a sacrifice to seek for rainfall, health and good harvest in society. The clan leaders such as chiefs who, in most cases, were also religious leaders and traditional doctors/healers, painted or commissioned artists to paint on the rock surfaces during prayers for good harvest, health and rainfall, an image of the animal that was slaughtered at the site as a sacrifice. An intensification of the sacrifice depended solely on how long the painted image would stick and stay intensively visible on the rock face. Chiefs and elders were also glorified by using rock paintings, and that was another reason for the existence of Rock Arts. According to Masao (2003), there were symbols that were painted on rocks which were associated with heads of clans, such as symbols of a spinal column, which appears as an emblem of chieftainship almost all over the south of Lake Victoria. The rock paintings, according to Masao (2015), played a role of motivation or sympathetic magic. They used to lure animals during hunting because it was a belief that the effectiveness of hunting depended to a large extent on the resemblance of the painted image to an intended animal. Precisely, the more resembling to an 
animal the painting is, the more effective the hunting would be. Therefore, in the societies that practiced hunting, people used to paint images of animals to get motivated before going out hunting. Third, the Rock Art was done to preserve information and culture. These paintings, with a good citation being the Bushmen, were also used to preserve information and culture by keeping the records of all the animals or things these people came across.

Although the greatest contribution that Africa has made so far to the cultural heritage of mankind, especially in the modern art of the western world, is its richly varied sculpture. People often forget that painting and engraving are the earliest art forms the continent has ever created. The Tanzanian Rock Art, believed to be the oldest in Africa (Masao, 2003, p. 21), has attracted world academic attention since 1923 when Bagshawe published a paper in Man entitled 'Rock Painting of the Kangeju Bushman.' But a German colonialist, Karl Peters, is said to have seen Tanzanian Rock Art in his various travels in central Tanzania since 1891 (Anati, 1986, p. 25). To most westerners of the time, however, Rock Art was a 'puzzling curiosity' as modern Makonde sculpture is to some western writers such as Kasfir (1999, p. 109), or as the Ife Royal sculpture created in the 12th century $\mathrm{CE}$ is to some western art skeptics. All these examples represent the attitude held by some western 'doubting Thomases' on the capability of the African to paint, to create modern sculpture that is not a commodity and to create realistic figurative sculpture.

The largest concentration of Rock Art of Tanzania, according to Masao (2003, p. 22), lies in the central plateau, especially in the Kondoa District in the Dodoma Region, the Iramba District in the Singida Region and Mbulu District in the Manyara region, as can be seen on the map (Figure 1). The occupants of such areas are the Sandawe, Hadzabe, Tatoga, Nyaturu, Nyiramba, Irangi, Gogo and Iraq tribes. According to Anati (1986, p. 18), 'The Eastern part of Africa, from Eritrea to Mozambique, has so far revealed a scattered distribution of Rock Art zones with a major concentration in central Tanzania.' Anati reports that Tanzania has over 370 sites and over 550 rocks, shelters and caves that are decorated. The central highland areas

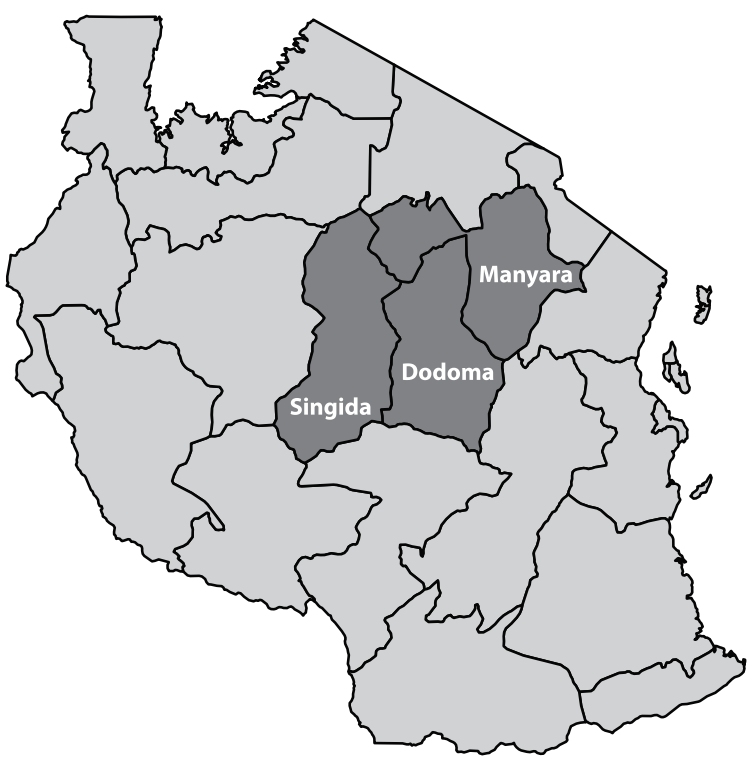

Figure 1 Map of Tanzania: Areas with most concentration of Rock Art in central Tanzania

only have around 330 sites, of which 200 have been recorded. Other areas in Tanzania with rock sites include the Kilimanjaro district, the Usambara Mountains, the Ukimbu district, Nachingwea and Masasi (Anati, 1986, p. 23).

According to my phone interview with Prof. E. Jengo (2015), the ancestors of these ethnic groups are supposed to be the authors of the Rock Art we see today, and they were made up of four distinct horizons or groups. These were Early Hunters and Gatherers (HGE), Late Hunters and Gatherers (HGL), Pastoralists (PA) and Farmers and Mixed Economy (FM).

The HGE was the oldest stage, which seems to have been neglected because the paintings are faded and barely seen in many areas except Kondoa and Singida in central Tanzania. The art is believed to have been done over 40,000 years ago because, among the major stylistic phases of this art that was detected, it is similar to those represented in the slabs of Apollo 11 cave, in Namibia, which has evidence of using coloring pigments dated between 47,000 and 50,000 years ago. The figures in this category seem to represent wild animals such as giraffe, elephants, warthogs, buffalo, rhino, hyena and wild dogs, which are depicted in representational naturalistic and semi naturalistic 
styles. They are mostly shaded in red ochre, paint, ashy or latex white, and rare black lines shaded with brown. Such depictions, according to Masao (2003), are known as zoomorphic figures. Reptiles in this category include snakes, lizards, crocodiles, and tortoises, as well as fishes.

The HGL category, in which paintings are estimated to be about 10,000 years old, features human figures known as anthropomorphic figures. They are presented in highly stylized or abstract forms and poorly drawn silhouettes with less anatomical details. The figures are often depicted in small groups or pairs rather than individuals, and are drawn in single thin and thick lines. In most cases, they appear to be associated with some kind of activity. The human figures are presented in a dynamic and stylized way, sometimes with bows and arrows in their hands, which can also be categorized in the group of paraphernalia or equipment. Masao (2003, p. 24) categorizes paraphernalia and equipment in the picture cluster of bows, arrows and spears. Likewise, paraphernalia and equipment are also suggested by Leakey (1983, p. 43), to represent ethnographical objects such as a fish weir, bird cage, trap or the skeletal woodwork of a hut.

This group of late hunters and gatherers is subjected to mythology and human daily activities, such as hunting. By the way, hunting has been very common and widespread in many societies that are found in central Tanzania.

Interestingly enough, these rock paintings reflects the occupations of each of these early communities. According to Mwenesi (2006), 'The drawings and photographs of rock art portray vividly the dynamics of the day-to-day lives of these ancestors.' For example, Anati (1986, p. 19) shows that wild animals and ideograms painted on vertical rock surfaces were the work of the HGE group, while the HGL community also occupied themselves with painting humans and wild animals on vertical rock surfaces. 'The precise depiction of human beings and animals such as elands, elephants, giraffe, rhinoceros, lions, and cheetah, help us to visualize the type of environment these people lived in, and struggled against' (Mwenesi, 2006, p. 101). The images seen in these areas provide evidence that those ethnic groups were hunters, gatherers, pas-

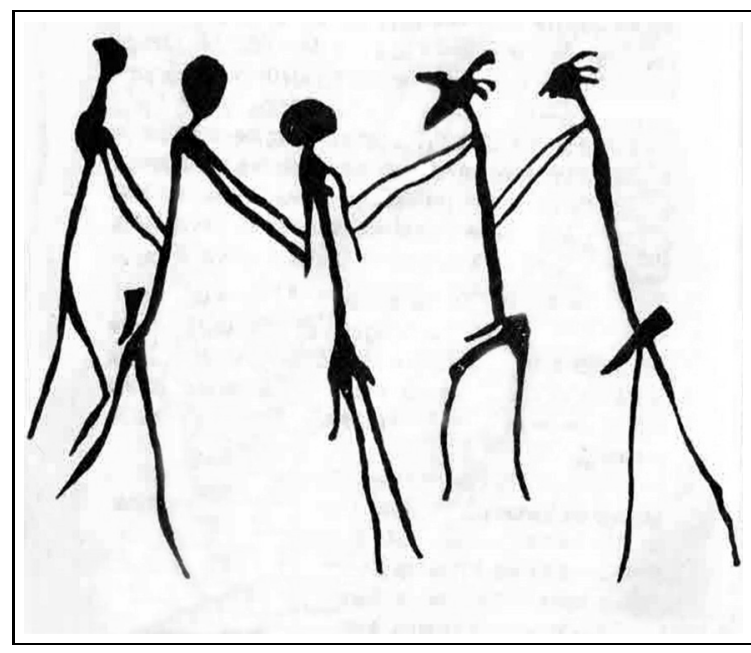

Figure 2 Paintings from Kondoa Rock Sites

(Ntiro, 1982, p. 32; reproduced with permission from Tanzanian National Arts Council)

toralists and farmers. Ntiro (1982, p. 32), for instance, portrays one of the rock paintings which shows five human-like images, whereby two male figures on each side pull a female figure in the middle. This composition can be decoded from different perspectives with a number of translations, depending on the viewer's historical background and life experience. However, Ntiro (1982) decodes the composition as boys' contest to win a girl. The image suggests that the males on the right-hand side are two boys in masks trying to take the girl (in between) by force from her two brothers on the left with bare heads. The presentation of the two male figures on the right appearing in masked faces and strange heads is interpreted as enemies trying to steal the girl from her family. It is obvious even nowadays to see people appearing in covered faces when engaging in a wrong or unacceptable attempt, such as stealing or robbing. Moreover, the artist presents the two strangers with erect penises to show their need and readiness for the girl, which drives them crazy to the extent of using force trying to grasp her from her brothers. The image evidences that, although people did not speak the languages that we speak today, they had a way of communication.

Ntiro's translation reflects today's many Tanzanian and African societies, in which, according to their tra- 
ditions; girls usually leave their families and move to their husbands after marriage. However, under normal circumstances, this task has never been easy for the girl's family. Girls' family members, including parents, brothers, sisters, and other extended family members and guardians such as grandfathers and mothers, uncles and aunts, know for sure they would be missing their beloved one. Therefore, there is usually a kind of resistance, which is mostly caused by a strong bond among these family members. When a boy wants to marry, therefore, his family should convince the girl's family by first being nice to the girl's family, and second, giving a bride price, which is normally a certain number of cows, goats, money and/or other valuable goods, depending on the inquiry, norms and customs of the girl's culture. So, the knowledge we get today from studying rock paintings which were done thousands of years back does not only remind us of the civilization that had been part and parcel of human existence since prehistoric times, but also tells us that Tanzanian artists of today and their works, build another foundation of the future Tanzanian history.

The PA group, which is concentrated mainly in Kenya and Tanzania, portrays naturally engraved and painted domestic animals on oblique, as well as vertical, rock surfaces. The paintings featured animals such as cattle, goats, sheep and dogs, which are commonly painted in black, white and brown colors. Again, there are also geometrics, which are presented by lines, squares, ladders, circles, dots and doodling, which suggest having cattle ownership by pastoralists.

Some characteristics of these paintings, according to Anati (1986), seem to reflect second millennium в C features to suggest that the style was common or introduced during that time. Most of the features are associated with the Stone Age Bowl culture.

The F M category, which is reflected in today's Bantu speaking people, particularly in some societies of Kenya, Tanzania, Mozambique, Uganda, Malawi, Zambia and Zimbabwe, was engaged in pattern and symbol making on cave floors, roofs, walls, vertical and horizontal rock surfaces. These societies are connected to initiations and ancestral worship. Schematic designs, which are principally in white and cover the last 2,000 years, comprise these societies. In this category, the paintings are featured by ideograms (graphic symbols that present an idea or concept) and abstracts. Masao (2003, p. 23) categorizes this type of paintings as geometric figures, which are non-representational paintings, possibly with completely different ideas from geometric purpose and representation. They were represented by lines, squares, ladders, dots and doodling, circle and rays, concentric and spiral. Neither humans nor animals were involved in this category. It is believed that artists hesitated to paint human figures because of their religions and spiritual beliefs. According to Masao (2003, p. 24) the ideograms and abstracts would be comparable to the pastoralists' cattle ownership signs. Today, people who live in the areas rich in rock paintings, including Sandawe, are mixed farmers with large herds of cattle.

The rock paintings and engravings confirm the thinking of Masao (2003, p. 21) when he writes, 'As we study Rock Art, we are dealing with intellectual concepts, emotional expressions in differing states of consciousness and aesthetic tastes of early people, in other words, with the spiritual rather than the material aspects of a culture.' Indeed, a careful observation of the drawings and paintings of the human figure by the rock artists reveals interesting stylistic contrast with that of animals. The animals are painted in a realistic manner while the human figure is often drawn in an abstract style, hence begging the question, 'What determined the difference?' However, the answer is not hard to find in that, throughout the ages, the human image in art has been frowned upon for religious or magical reasons. It is, for example, speculated that the rock artists had to draw the human figure abstractly for fear that if he/she drew a realistic human figure and a neighbor lost a relative, then he would be regarded as a witch capable of copying human faces. Another example refers to our time when the use of icons brought about the Iconoclastic controversy that divided the Catholic Church into two halves: The Orthodox Eastern church and the Roman Catholic faith. The breaking of icons in former Catholic churches in Germany during the Reformation was another battle that was raged against icons. The overall reason is how people interpret the controversial Biblical command given to Moses that reads, 'You must not make 
for yourself a carved image of a form like anything that is in the heavens above or that is on earth underneath or that is in the waters under the earth.' (New World Translation of the Holy Scriptures, 1961, p. 93). Although the rock artists did not live in a community with an organized religion, it is often believed by some archaeologists that the clan had authority to enact laws to bind it together, and drawing the human figure in an abstract way may have been one of them. These people are our ancestors, and with their rock paintings and engravings Tanzania's history of art begins.

\section{Tourism}

Tourism, according to Bailey and Richardson (2010, p. 367 ) is one of the largest economic sectors in the world, which represents approximately $6 \%$ of the global export. In Tanzania, tourism is glorified as the biggest source of securing income. Tourism, according to Anderson (2015), who quotes the 2011 National Visitors' Exit Survey Report, contributes 18\% of the country's Gross Domestic Product (GDP) by earning around US \$ 1.35 billion in 2011 and Us \$ 1.7 billion in 2012 . The traditional attraction sites, which are the natural tourist attractions, have remained to be the national parks, conservation and game controlled areas, which, according to Anderson (2015), accounts for more than 90\% of tourist arrivals in Tanzania. To date, there are many such natural attractions for domestic and foreign visitors to visit and see a variety of fauna and flora. Some of those attractions include Ngorongoro Conservation Area, Selous Game Reserve, and the National Parks of Serengeti, Mikumi, Lake Manyara, Tarangire, Arusha, Saadan, Ruaha, Katavi, Mkomazi, Udzungwa, Rubondo Island, Kitulo Plateau, Gombe Stream and Mahale Mountains. The man-made tourist attractions in Tanzania, according to Lwoga (2012, p. 23), include the Kondoa Rock Art Sites, Zanzibar Stone Town, Bagamoyo historical town, Kilwa Kisiwani and Songo Mnara, Dar es Salaam city and its Museums, Olduvai Gorge, and many others. They provide employment to hotel owners, game scouts, wardens, art and crafts dealers, tour guides, wild life photographers and film makers.

A full Ministry of Natural Resources and Tourism has been established to deal with the management of natural and cultural heritage resources. However, the impact of the Antiquities Department, which is directly responsible for Rock Art in the context of initiating innovations to promote Rock Art sites, has yet to be felt at maximum level as popular attractions for tourism. This shortcoming is the major reason for writing this paper. Let us now discuss the measures that may alleviate the shortcoming, which are part of the efforts made to strengthen cultural tourism in the country.

\section{Rock Art and Cultural Tourism}

Despite the fact that Rock Art has all the potential for cultural tourism, it has not been involved much in the promotion of cultural tourism. Cultural tourism is conceptualized in Wineaster Anderson's report on Cultural Tourism and Poverty Alleviation in Rural Kilimanjaro, Tanzania, as having 'various symptoms, such as heritage tourism, arts tourism, ethnic tourism and other elements of learning that enables tourists to experience other people's way of life (values, norms, beliefs, traditions, etc.) in their natural environment (Meethan, 2003; Richards, 2011)' (Anderson, 2015). This quotation categorizes the Rock Art in a group of cultural tourism because the Rock Art is 'art' itself, heritage, and enables tourists to experience Tanzanians' values, norms, beliefs and traditions. Anderson's paper goes further and reports that cultural tourism has failed to demonstrate its potential to alleviate poverty of people in the surrounding areas (Anderson, 2015). It has been like that for over four decades. This lack of interest, specifically for Rock Art has been recorded in the report on Rock Art of Tanzania prepared by Emmanuel Anati, the Director of the International Committee on Rock Art, who was commissioned by UNESCO in the 1980s to conduct research on Rock Art in Eastern Africa. He writes,

The Rock Art of central Tanzania has not yet been discovered fully. Only now are we beginning to grasp its significance in relation to world history and to the world's cultural heritage. It is still almost ignored in the general history of Africa. Often it is seen as an undated 'curiosity' by old fashioned archaeologists, and, until recently, was considered unimportant by most of the Tanzanians themselves. The record of visitors, which 
is kept at Kolo, shows that since 1959 between 120 and 400 annual visitors have come to see the sites, with peaks of 616 people in 1972 and of 562 in 1973. Obviously, this cultural patrimony is as yet little known and has not been given the importance it deserves, despite the keen interest of several archaeologists and the constant concern of the Department of Antiquities. And yet it appears to provide one of the longest uninterrupted chronological sequences of artistic creativity in the world. As we shall see, it is likely to include the earliest paintings known in Africa and perhaps in the world, and provides unique documentation of man's way of thinking, his intellectual achievements, the imaginative world and cultural changes which took place in the societies of eastern Africa during the last 440,000 years. (Anati, 1986, p. 24).

Anati has been quoted at length so as to show the significance of Tanzanian Rock Art and the place it occupies in the evolution of man's culture. As the established cradle of mankind, Tanzania should maximize its potential in proving to the world that the country has enough evidence to support such a view. According to Mapunda (2013, p. 81) the rock paintings in the rock sites of Kondoa, central Tanzania, have been noted to vanish at an alarming rate due to both natural and cultural factors. The natural factors include animal droppings, rainwater, seepage and exfoliation, whereas the cultural factors include graffiti, touching, splashing with local brew (for ritual purposes), illegal excavation in the rock shelters, dusting and soot.

Let us now examine measures that can be taken to make Rock Art a true attraction to domestic, as well as foreign, tourists. The management measures that should be taken to attract tourism to these sites should go in line with protection of the sites from ground dust and rain water that deteriorate the paintings. In her book, Africa's Vanishing Art, Leakey (1983) predicts that these Rock Arts are likely to be destroyed by the year 2020, if serious management measures are not taken. The author suggests that, to make such a conservation project successful, the measures should fully involve people who dwell around the sites in order to get their support and commitment to the project. Failure to involve the local community might end up in unsuccessful investment of the project. The Antiq- uities Division of Tanzania, for instance, according to United Republic of Tanzania $(1965,2014)$ and Bwashiri (2011), carried out a conservation project of this kind between 1965 and 1968 in the Kolo-Kisese Rock Art sites, which were considered to be at a high risk of destruction. However, the project, which involved fencing the rock paintings by using a wire mesh, was not successful because of an inappropriate operational approach. The local community was not, or was partially, involved in the project. Members of the community, who have less or no education in Rock Arts, were not equipped with enough knowledge on the rationale of such conservation. As a result, this project did not get support from people living in that area. According to Mapunda (2013, p. 82), the project suffered heavily from vandalism from some members of the local community, who removed not only the wire mesh, but also nuts, timbers and locks, that used to support the wire mesh, and used them to renovate their house windows. These people from the local community did not see why such expensive material (wire mesh, timber and nuts) should be left in the jungle protecting the rocks, which are less important to them.

\section{Methodology}

The aim of this article was to give suggestions which would popularize the Tanzanian Rock Art sites and make them tourist attractions. The central plateau, which includes the Kondoa, Iramba and Mbulu districts in the Dodoma, Singida and Manyara regions respectively, was used as the case study because it has the largest number of Rock Art sites in Tanzania. According to Anati (1986, p. 23), the central part of Tanzania has over 330 sites out of 370 sites located in the entire country. That means over $89 \%$ of all the Rock Art sites which are located in Tanzania are found in the central plateau. The source from which data was collected for writing this paper includes library research and some minor interviews and observations. The qualitative data were analyzed through descriptive analysis.

The author is particularly grateful for the work done by Professor Emmanuel Anati (1986). It was from him, to a large extent, that the problem of this study was formulated. Anati showed that the amounts of 
visitors to Rock Art sites was dwindling year by year. Therefore, the research question for this study was how do we initiate innovations to promote Rock Art sites as popular tourist attractions in Tanzania, at maximum level? In answering this question, the author attempts to offer possible solutions to the problem.

Unstructured interviews were used in this study. Phone interviews were conducted in April, 2017, with five Tanzania Tourism Board (т т в) members, who are responsible for the promotion of tourism in the country. The two main questions in the interview were as follows: Are there any plans to build tourist resorts close to important Rock Art sites? To what extent have you created awareness of the accessible Rock Art sites? The rationale for asking these two questions was based on the fact that, by bringing tourists close to the Rock Art sites, the world will recognize the earliest sources of painting and drawing that took place in Tanzania over 40,000 years ago. The second question was based on the fact that the general public knows very little about Rock Art. Therefore, by making it popular through official means by the relevant authority, tourists will be attracted to visit the sites.

In terms of observation, the author applied a participatory method by visiting the Jiangxi Provincial Museum in China and the Qana/Cana Grotto site in Lebanon. Although these visits were not initially meant for this particular study, the author found them useful, because they provide relevant information for the study. The author got a chance to visit the Qana/ Cana Grotto site when he went to Lebanon for a vacation in the summer of 2005. The author again had a chance to visit the Jiangxi Provincial Museum in November, 2016, following an invitation from the Chinese Department of Culture through the University of Dar es Salaam in the context of promoting cultural cooperation between Tanzania and China.

\section{Responses from the Interviews}

The respondents were members of the Tanzania Tourist Board (ттв), who responded that the Tanzania Tourist Board had never given Rock Art sufficient emphasis as an item of the tourist attraction. There were no reasons given for such an attitude. This confirms what Anati had written 31 years ago about the impor- tance which had been given to Rock Art in Tanzania. The visitors' record that is kept at Kolo shows between 120 and 400 people visited the Rock Art sites annually from 1959 to 1971 with peaks to 616 people in 1972 . The figure began to diminish to 562 people in 1973 (Anati, 1986, p. 24). These figures are very small compared to those in the traditional tourism, which is given a priority in terms of promotion as a tourist attraction. According to Lwoga (2011, p. 129) the overall figure of tourists, which includes Rock Art and traditional tourism, from 1959 to 1971 ranges between 7,880 and 68,400 people with peaks to 199,200 in 1972 and diminishing to 143,500 in 1973 . These figures make a clear picture that there were more tourists who visited other areas apart from Rock Arts sites, and that reflects the insufficient emphasis given to the Rock Art sites.

The response to the second question was also negative. The five respondents confirmed that they have never contacted investors to build resorts at important Rock Art sites. This shows very clearly that many institutions are not aware of the potential of Rock Arts sites in Tanzania as tourist attractions.

\section{Author's Observations on Cultural Tourism}

During the visit to the Jiangxi Provincial Museum in China, the author of this study and other visitors were taken around the museum by professional guides who were conversant with every display in the Museum, and explained in detail the significance and history of each and everything that was displayed. Likewise, in Lebanon, the author visited the Qana/Cana Grotto site, 10 kilometers southeast of the city of Tyre in South Lebanon, where there were also guides to take visitors around this cultural site. There were a lot of people visiting this cultural heritage site, at which Jesus is said to have done the miracle of turning water into wine.

Publicity: It may seem that Rock Art of Tanzania is only relevant to researchers and students of archaeology judging from the publications available in the nation's libraries, but this is far from the truth. The Ministry of Natural Resources and Tourism, through its Antiquities Department, which is responsible for managing Rock Art, should find a better way to reach a wider community with information on the significance of Rock Art to the country. The Ministry could 
use media as a platform to reach a wider community by disseminating important information about the Rock Art. This would make people aware and appreciate this Tanzanian cultural heritage. In addition, reading materials such as pamphlets, magazines and leaflets should be used to publicize this cultural heritage. These reading materials should be distributed in public areas such as hotels' lounges, restaurants and local and international flights for people to read.

The author acknowledges some public institutions like the National Museum and House of Culture for setting aside a special room for Tanzanian rock paintings to enable the general public to view their cultural heritage. However, the display is not focused on any aspect of knowledge that would make the ordinary person appreciate the significance of rock paintings in the cultural development of today's Tanzania. Although the Museum should be commended for setting aside a space for the display of cultural heritage of universal value, it should also take steps to either put professional and reliable guides to explain to the visitors the significance of the display, or have a public address system that would communicate useful information at intervals to the public. Countries like China and Lebanon, for instance, have taken such steps by employing full time professional guides in their $\mathrm{Mu}-$ seums and cultural sites. The professional guides take time to explain the significance of each display in the museums and sites to visitors.

Hotels and Camps: Given that Tanzania is rich in Rock Art where 370 sites have been reported, would it not be convenient to build hotels and camps near the sites to attract visitors? At the Ngorongoro Crater area there are hotels for visitors wishing to view game. The same spirit should guide our tourist management officials to view Rock Art as an important part of cultural tourism that needs shelters for visitors to stay in order to appreciate it fully. Such important sites as Mongomi wa Kolo in Kondoa, central Tanzania, which, according to Bwashiri (2008, p. 22), is the main visitor attraction to the Kondoa World Heritage Site, and where the most famous painting called The Abduction Scene of the HGL style is located; or Msaghaa in Singida, where artworks of the FM groups are still preserved in caves, are but a few of the interesting areas where camps and hotels could be erected. Camps and hotels around the Rock Arts sites would also create jobs to the local community members and encourage other economic activities. This would play a major role in alleviating poverty among the community members, as mentioned by other scholars. Cole and Buhrich (2012, p. 71), for instance, mention that rock art tourism is a global phenomenon and, in many parts of the world, is contributing to community development and regional economies. The hotels and camps around the Rock Art sites would definitely need employees with different skills and educational levels. Local community members would take jobs such as house-keeping, guards and drivers which, in most cases, do not require a high level of education. It should be known that these sites are located in rural areas with few or no schools and, hence, the majority of people who reside there have not attended schools. The participation of Micro and Small Enterprise (MSE) in tourism, according to Mshenga and Richardson (2013, p. 168), has a great potential to economic development and poverty alleviation. The two scholars (Mshenga \& Richardson, 2013) studied micro and small enterprise participation in tourism in the coastal region of Kenya after realizing that such participation has recently become the subject of research and policy analysis. The study found that participation of small business in tourism can, in some circumstances, contribute to poverty reduction.

Another study by Professor Winiester Anderson shows that cultural tourism can play a major role in improving the lives of people living around the tourist sites by creating jobs and encouraging other economic activities. She evidences in her research on how cultural tourism could be the factor for poverty alleviation. Professor Anderson found that enterprises such as hotels, lodging houses, restaurants and curio shops are largely involved in tourist-related activities. Tourists who visit tourism sites usually need accommodation in hotels and lodging houses, meals and souvenirs, which, in most cases are provided by local people living around the tourism sites. According to Anderson (2015) 'enterprises are largely involved in tourist-related activities, which include the provision of accommodation (hotels and lodging houses) 
and restaurants $[\ldots]$ and sale of souvenirs, pottery and earthenware.' Duval and Smith (2014) emphasize the need of accommodation in the site areas in their paper which discusses the steps towards the development of Rock Art tourism. Duval and Smith's paper, in which research was conducted in the region of uKhahlambaDrakensberg Park (U DP) of South Africa, aimed to determine the ways in which tourism can contribute to the preservation of Rock Art sites. According to Duval and Smith (2014, p. 44), after the first step, which is to designate an organization responsible for developing sustainable Rock Art tourism by beginning with allocating all the Rock Art sites, the next step should be to create a network of all the organizations and individuals who can contribute to the development of Rock Art tourism, which include accommodation providers, tourism service providers and local communities, as well as marketing and development professionals.

However, Tanzania has designated the Ministry of Natural Resources and Tourism to manage natural and cultural heritage resources through its Antiquities Department. Duval and Smith continue by saying that the whole process of developing sustainable Rock Art tourism should have a back-up of substantial political and financial support. This should not be the case for Tanzania, since the country is well known for its political stability, which supports infrastructures such as hotels and camps in the Rock Art sites. The government would benefit from collection of revenue in all these economic activities, which could be used to improve infrastructures such as roads, and social facilities like schools. Investment of camps and hotels, therefore, is as an opportunity for the local community members to benefit from schools. The pressure to build hospitals would more likely come from visitors who need this facility when they visit the sites. In another instance, the hotels might be offering health insurance for some of their staff members. That situation will increase the pressure to build hospitals in the areas as staff would also need these facilities.

\section{Learning from Others}

Evidently then, if the world has recognized Tanzania as having the largest concentration of rock art that cov- ers 200 square miles with 370 sites of rock art out of which 200 have already been recorded, (Anati, 1986, p. 23), what initiatives should the Tourist Board take in promoting the art? Should they visit other places to learn how this neglected art is promoted? Yes, the Tourist Board Members should visit countries that are doing well in promoting their cultural heritage such as Lebanon, China, France, Norway and South Africa, to learn their cultural tourism promotion techniques. If the rock arts site of Chauvet, for instance, was discovered only in 1994 in France, but is now among the greatest tourist attraction sites in Europe, it is, therefore, possible to make the Tanzanian central plateau rock arts, which are over 40,00o years old, popular and great tourist attraction sites in the world.

The interviews showed that the Tourist Board members have made several visits to other places such as Malaysia, India, Egypt and South Korea as part of their efforts to see how other countries are promoting their tourism attraction sites. The author learnt that, through such visits, the promotion of the traditional tourism sites has been doing very well in Tanzania. It is time to apply the same traditional tourism promotion skills to these cultural heritage sites.

In northern Norway, there are Rock Art sites and some institutions are built close to them. In order to create awareness among students of the importance of their cultural heritage, some of the institutions make and use logos that depict Rock Art. In Tanzania, some big medical institutions are built in the same premises with hospitals to make it easy for medical students to practice what they learn in classrooms. Among those medical institutions are the Muhimbili University of Health and Allied Sciences (MUHAS), which is built in the same compound with the Muhimbili National Hospital in Dar es Salaam; the Catholic University of Health and Allied Sciences (K U HA s), which is also built nearby the Bugando Referral Hospital in Mwanza; and the Kilimanjaro Christian Medical University ( $\mathrm{KCMU})$, which is built by the Kilimanjaro Christian Medical Center (ксмс) in Kilimanjaro.

If archaeology, art and history academic institutions would be built nearby the rock sites, it would not only give students a chance to practice what they read in books and learn in classrooms, but would also in- 
crease awareness among these students about the importance of their cultural heritage. These institutions would make and use logos/emblems that depict the Rock Arts found in the sites that are affiliated with such institutions.

Monitoring skills is a dispensable tool for proper conservation of the rock paintings that could be earned through such visits. According to Jopela (2010, p. 58), regular monitoring activities would enable site conservators to determine causes of site deterioration and address appropriate measures to mitigate site damage. The Rock Art site (в N 1) in the Clocolan district, Free State Province in South Africa, is a good example of Rock Art sites which are monitored regularly, and the ттв could visit the site to learn proper monitoring strategies.

If appropriate measures are taken, the paintings on the rocks will not 'fade out.' According to Jopela (2010, p. 66), the faded appearance is usually due to pigment loss or discoloration, which is caused by salt growth and a cover of a mineral layer. If regular monitoring is practiced at the Tanzanian Rock Art sites, the paintings' fading and deterioration can, therefore, be decreased. Monitoring is also mentioned by Duval and Smith (2014, p. 45) as a process to measure changes in the position of art in uKhahlamba-Drakensberg Park tourism. They emphasize that the monitoring process should also include visitor numbers to Rock Art sites, and the place of Rock Art in promotional materials.

\section{Conclusion}

Tanzania is blessed in having the largest concentration of Rock Art in Eastern Africa, but its potential has not yet been realized by those entrusted with the task of tourism promotion. The contribution of Ngorongoro Conservation Area, Selous Game Reserve, and national parks of Serengeti, Mikumi, Lake Manyara, to mention a few, in Tourism promotion is acknowledged fully by the author, but innovations are always in place if diversification in promotion approaches is needed for rapid development of tourism promotion. Family economic growth of local people would also be a factor, since people living around the site areas would have a better opportunity to sell and supply goods and services to tourists who visit the sites. It should be noted that the majority of rural families in Tanzania, where these sites are found, according to United Republic of Tanzania (2010), cannot afford their basic needs such as food, education, health services and shelters without support from the government, NGOs, friends or relatives. So, effective tourism promotion in these areas could be another way of supporting these people. If these Rock Art sites, which, according to Mapunda (2013, p. 81), are among the country's economic resources, are exploited strategically, it could alleviate the scorching poverty of the country within a short period of time. We live in an age when a people's perception of the origins of their visual arts can influence the historical development of their arts deeply. The development of the art of painting and drawing in Tanzania should be glorified as the earliest art form of Africans, and not the art of sculpture, which made its presence felt in the world much earlier in the nineteenth century than painting. Making Rock Art a cultural tourism would also be a way of preserving and restoring such cultural heritage. This would attract people from all over the world to visit the sites as tourists and develop awareness of the country's conservation. Regulatory measures and bylaws, according to Lwoga (2011, p. 32), would be set in the tourist destinations, which would also help to conserve the environment and its resources. This should go in-line with regular monitoring of the sites, which, of course, should be based on a negotiated partnership with people living around the sites, to determine condition change of the paintings and take necessary measures.

Finally, if we are to succeed in making Rock Art a popular attraction for tourism promotion, we must first teach our people in schools and elsewhere about the cultural and intellectual significance of Rock Art. It is possible that those responsible today for promoting tourism might not have been exposed to a curriculum that included topics on Rock Art among other things. As a result of this anomaly, Rock Art has remained a neglected subject by the general public, but an elitist discipline to art historians and some museum staff. This needs our urgent attention. The Ministry of Natural Resources and Tourism, which is responsible for managing natural and cultural heritage resources 
through its Antiquities Department, should advise the Ministry of Education, Science and Technology to include a topic about Rock Art in primary and secondary schools' curricula. This suggestion should go together with the proposal of building academic institutions, especially those dealing with arts, history, and archaeology and heritage management, near the Rock Art sites to allow students to do practical and field training on the sites.

Besides, local community members should also be given education about the significance of their cultural heritage through media, seminars, workshops and schools (for children). They should also be involved fully in Rock Art conservation projects from brainstorming processes rather than only waiting to see implementation of the projects in their areas. Duval and Smith (2014, p. 45) insist that local communities have to be involved because they are the people most able to benefit from increasing the social value of sites, as they will then become true partners in developing Rock Art tourism. These people ought to be well informed about their cultural heritage, and they should be made to understand that it belongs to them. This would make community members know why such projects are important to them and their future generations. People who live around the Kolo-Kisese Rock Art sites, for instance, were more likely to support the conservation project which was implemented in their area, if they were involved in the project from the brainstorming process.

\section{References}

Anati, E. (1986). The state of research in rock art: The rock art of Tanzania and the East African sequence. Bolletino del Centro Camuno di Studi Preistorici, 23, 15-68.

Anderson, W. (2015). Cultural tourism and poverty alleviation in rural Kilimanjaro, Tanzania. Journal of Tourism and Cultural Change, 13(3), 208-224.

Bailey, E., \& Richard, R. (2010). A new economic framework for tourism decision making. Tourism and Hospitality Research, 10(4), 367-376.

Bwashiri, E. J. (2008). The management of indigenous living heritage in archaeological world heritage sites: Case study of Mongomi wa Kolo rock painting site, Central Tanzania (Unpublished Master's dissertation). University of the Witwatersrand, Johannesburg, South Africa.
Bwashiri, E. J. (2011). The implications of the management of indigenous living heritage: The case study of the Mongomi wa Kolo paintings world heritage site, Central Tanzania. South African Archeological Bulletin, 66(193), 6066.

Cole, N., \& Buhrich, A. (2012). Endangered rock art: Forty years of cultural heritage management in the Quinkan Region, Cape York Peninsula. Australian Archaeology, 75, $66-77$.

Duval, M., \& Smith, B. W. (2014). Seeking sustainable rock art tourism: The example of the Maloti-Drakensberg Park world heritage site. South African Archaeology Bulletin, 69(199), 34-48.

Jopela, A. (2010). Towards a condition monitoring of rock art sites: The case of BNE 1 in Free State Province, South Africa. South African Archeological Bulletin, 65(191), 5866.

Kasfir, S. L. (1999). Contemporary African art. London, England: Thames and Hudson.

Leakey, M. D. (1983). Africa's vanishing art: The rock paintings of Tanzania. London, England: Hamish Hamilton.

Lwoga, N. B. (2011). Tourism-meaning practices and history. Dar es Salaam, Tanzania: Dar es Salaam University Press.

Mapunda, B. B. B. (2013). Get off my land! Towards mutual understanding in archaeological field conflicts. AP: Online Journal in Public Archaeology, 3, 74-96.

Masao, F. T. (2003). The prehistoric rock paintings of Tanzania mainland. In Y. Goscinny (Ed.), East Africa art biennale (pp. 20-36). Dar es Salaam, Tanzania: La Petite Galerie.

Masao, F. T. (2015). The rock art in Tanzania [Powerpoint slides]. University of Dar es Salaam, Dar es Salaam, Tanzania.

Meethan, K. (2003). Mobile cultures? Hybridity, tourism and cultural change. Journal of Tourism and Cultural Change, $1(1), 11-28$.

Mshenga, P. M., \& Richardson, R. B. (2013). Micro and small enterprise participation in tourism in Coastal Kenya. Small Business Economics, 41(3), 667-681.

Mwenesi, L. C. (2006). Rock art and the national curriculum in Tanzania. Utafiti, 7 (1), 100-108.

New World Translation of the Holy Scriptures. (1961). Warwick, NY: Watch Tower Bible and Tract Society.

Ntiro, S. J. (1982). Asili ya Sanaa. In E. Jengo, L. A. Mbughuni, S. A. Kandoro (Eds.), Falsafa ya Sanaa Tanzania (pp. 2843). Dar es Salaam, Tanzania: B As atA.

Richards, G. (2011). Creativity and tourism: The state of the art. Annals of Tourism Research, 38(4), 1225-1253.

United Republic of Tanzania. (1965). Annual Report of the 
Antiquities Division for the Year 1965. Dar es Salaam, Tanzania: Author.

United Republic of Tanzania. (2004). Kondoa rock art site: Nomination of properties for inclusion on the World Heritage List. Dar es Salaam, Tanzania: Author.

United Republic of Tanzania. (2010). National strategy for growth and reduction of poverty II. Dar es Salaam, Tanzania: Author.
Willet, F. (2002). African art. London, England: Thames and Hudson.

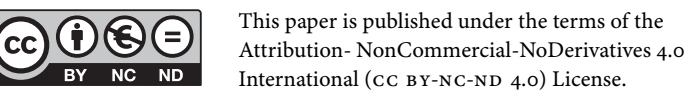

